\title{
SUPPLIER SELECTION AND ORDER QUANTITY ALLOCATION OF RAW MATERIAL USING INTEGER LINEAR PROGRAMMING
}

\author{
Ika Deefi Anna ${ }^{1}$, Putri Rani Fhiliantie ${ }^{2}$ \\ 1,2 University of Trunojoyo Madura, \\ Jl. Raya Telang PO BOX 2 Kamal, Bangkalan 69162, Indonesia
}

\begin{abstract}
The production activities of a company are influenced by sufficient availability of raw materials. The availability of raw materials will be fulfilled if the supplier regularly sends raw materials in accordance with the planned delivery time. However, each supplier has different capabilities in terms of supply capacity, price, product quality, and delivery time. Determining the right supplier will help the company maintain its production process. This study aims to identify which suppliers are selected to fulfill the demand for each production period and determine allocation of raw material orders to each selected supplier. The model developed to determine selected suppliers have been an integer linear programming. The model has the objective function of minimizing the total cost which consists of purchasing, ordering and holding costs. The constraints include supplier capacity, order quantity allocation, demand, inventory balance, safety stock, timely delivery, non negative and binary. Calculation results in giving a numerical example shows that the developed model is able to select suppliers per period. The model is also able to determine the allocation of raw material orders to selected suppliers. Sensitivity analysis is done to find out which parameters are sensitive. The results of the sensitivity analysis indicate that the parameters of supplier capacity and demand are sensitive parameters.
\end{abstract}

Keywords: Supplier selection, order quantity allocation, integer linear programming.

\section{INTRODUCTION.}

The production activities of a company are influenced by sufficient availability of raw materials. The availability of raw materials is strongly influenced by the suppliers. If the suppliers deliver raw material regularly according to the time of delivery, the availability of raw materials will be guaranteed. Determining the right supplier will help the company maintain its production process. The selection of the right supplier can increase the company's competitive advantage (Tsai et al., 2010) and is an important activity in the procurement activity (Amid et al, 2011). The company's production management and quality control require the suppliers (Yang and Cheng, 2006).
Several mathematical programming models have been proposed to solve the supplier selection problem. The proposed model used the optimization techniques can be classified as follows : linear programming, mixed integer programming, and multicriteria optimization (Mendoza and Ventura, 2012). The most important criteria for supplier selection are price, quality and delivery time (Moore and Fearon, 1973). Anthony and Buffa (1977) developed a single objective linear programming model to support strategic purchasing scheduling. Narasimhan and Staynoff (1986) developed the single objective mixed integer linear programming to optimize the allocation procurement to suppliers. Mixed integer linear programming was used to minimize the total cost of 
supplier selection with price break (Chaudhry et al, 1993). Mixed integer linear programming also was used to solve supplier selection and order quantity allocation (Jayaraman et al, 1999). Ghodyspour and O'Brien (2001) developed mixed integer nonlinear programming model to select and property allocates orders to suppliers.

\section{MATERIALS AND METHODS}

This study aims to determine selected supplier and allocation of order to the selected suppliers. Determination of the selected suppliers and order quantity allocation is done by developing integer linear programming (ILP) model. The following are steps for obtaining the aims of this study:

1. Develop ILP model with constricting of the model components that include indexes, sets, parameters, decision variables, objective function, and constraint functions.

2. Do the verification and validation process to the model.

3. Solve the model using Lingo software.

4. Do the sensitivity analysis to find the sensitivity parameter.

\section{RESULT AND DISCUSSION.}

\section{Development of mathematical model}

The developed mathematical model is an Integer Linear Programming (ILP) model. The component of the ILP model consists of indexes, sets, parameters, decision variables, objective function, and constraint functions.

\section{Indexes}

Indexes used in this model are as folows :

$i$ : Index of period (week)

$$
i=1,2, \ldots, m
$$

$j:$ Index of supplier

$$
j=1,2, \ldots, n
$$

\section{Sets}

$M:$ Number of periods

\section{$N$ : Number of suppliers}

\section{Parameters}

$p_{i j} \quad$ : the price of raw material in the period $i$ from supplier $j(\mathrm{Rp} / \mathrm{pcs})$

$\mathrm{O}$ : the ordering cost of raw material during the period $i$ from supplier $j$ (Rp/order)

hi : the holding cost of raw material in period $i(\mathrm{Rp} / \mathrm{pcs} /$ period)

$d_{i}$ : demand of raw material in period $i$ (pcs)

$C_{i j} \quad$ : supplier's capacity in the period $i$ from supplier $j$ (pcs)

$S S_{i} \quad: \quad$ safety stock in period $i$ (pcs)

$L_{i \mathrm{j}} \quad$ : delivery time in period $i$ from supplier $j$ (days)

$L \quad$ : the maximum delivery time (days)

\section{Decision Variables}

$X_{i j}$ : the number of products ordered in the period $i$ form supplier $j$ (pcs)

$Y_{i j}$ : binary variable, order allocation in period $i$ from supplier $j$ \{ order allocation will be carried out to a supplier with a value of 1 and no order allocation to a supplier with a value of 0$\}$

$I_{i}$ : the quantity of raw material stored in period $i$ (pcs)

\section{Objective Function:}

The objective function in this model is to minimize the total cost (TC) which consists of the purchasing cost, the ordering cost and the holding cost.

\section{ILP Formulation}

\section{Objective Function}

$$
\operatorname{Min} T=\sum_{i=1}^{m} \sum_{j=1}^{n} p_{i j} X_{i j}+O \sum_{i=1}^{m} \sum_{j=1}^{n} Y_{i j}+\sum_{i=1}^{m} h_{i} I_{i}
$$

\section{The Constraints :}

1. The Capacity of supplier

$$
X_{i j} \leq C_{i j} \quad \forall i, j
$$


Supplier capacity is the supplier's ability to provide the raw materials needed by the company. Each supplier has a different capacity. The capacity constraint indicates that the quantity of raw materials ordered to suppliers must not exceed the supply capacity of suppliers.

2. Order quantity allocation

$$
X_{i j} \leq M C_{i j} Y_{i j} \quad \forall i, j
$$

Order quantity allocation is the determination of the quantity of raw material to be ordered to the supplier. Ordering the raw material to suppliers can be done if there is an order to the supplier.

\section{Demand}

$$
\sum_{j=1}^{n} X_{i j}+I_{i} \geq d_{i}, \quad \forall i
$$

The quantity of raw material ordered to suppliers is influenced by demand and the amount of raw materials in stock. So, The quantity of raw material ordered plus the amount of raw materials in stock must exceed the demands.

4. Inventory balance

$$
\begin{aligned}
& I_{i}=I_{i-1}+\sum_{j=1}^{n} X_{i j}-d_{i}, \quad \forall i \\
& I_{1}=I_{0}+\sum_{j=1}^{n} X_{1 j}-d_{1},
\end{aligned}
$$

The inventory greatly affects the production process. A large quantity of inventory will increase costs while a small quantity of inventory will disturb of the production process. Therefore, the balance of inventory needs to be maintained. The inventory quantity of the current period must be equal to the amount of inventory quantity in the previous period plus the ordered quantity minus the demand.

\section{Safety stock}

$$
\begin{aligned}
& I_{i} \geq S S_{i,} \quad \forall i \\
& S S_{i,}=0,05 * d_{i} \quad \forall i
\end{aligned}
$$

The inventory quantity of the current period must be greater than the safety stock.
Safety stock is set at $5 \%$ of demand per period. Safety stock of $5 \%$ of demand is an effort to prevent the shortages, defect and raw material damage during production process.

$$
\begin{aligned}
& \text { 5. Delivery time } \\
& L_{i j} Y_{i j} \leq L, \quad \forall i, j
\end{aligned}
$$

One of the criteria in selecting supplier is the delivery time by suppliers. The delivery time of the supplier must be less than the maximum delivery time.

$$
\text { 6. Binary } Y_{i j} \in(0,1), \quad \forall i, j
$$

The binary constraint shows that order allocation will be carried out to a supplier with a value of 1 and no order allocation to a supplier with a value of 0 .

7. Nonnegative and integer

$$
X_{i j}, I_{i} \geq 0 \text { and integer } \quad \forall i, j
$$

The result obtained must be positive and integer.

\section{The complete ILP model}

The complete ILP model is as follows:

$\operatorname{Min} T C=\sum_{i=1}^{m} \sum_{j=1}^{n} p_{i j} X_{i j}+O \sum_{i=1}^{m} \sum_{j=1}^{n} Y_{i j}+\sum_{i=1}^{m} h_{i} I_{i}$

Subject to :

$$
\begin{array}{ll}
X_{i j} \leq C_{i j} \quad \forall i, j & \\
X_{i j} \leq M C_{i j} Y_{i j} & \forall i, j \\
\sum_{j=1}^{n} X_{i j}+I_{i} \geq d_{i}, & \forall i \\
I_{i}=I_{i-1}+\sum_{j=1}^{n} X_{i j}-d_{i} & \forall i \\
I_{1}=I_{0}+\sum_{j=1}^{n} X_{1 j}-d_{1}, & \\
I_{i} \geq S S_{i,} & \forall i \\
S S_{i,}=0,05 * d_{i} & \forall i \\
L_{i j} Y_{i j} \leq L, & \forall i, j \\
Y_{i j} \in(0,1), & \forall i, j \\
X_{i j}, I_{i} \geq 0 \text { and integer, } & \forall i, j
\end{array}
$$




\section{Numerical Example}

This ILP model is used to solve the supplier selection and order allocation problem in CV ABC. $C V A B C$ is a company that produces plywood The main raw material for plywood manufacturing is short core.The availability of short core greatly influences the plywood's production process. During this time, CV ABC only considers the price criteria. Expensive prices do not always guarantee good product quality and delivery time. The raw material with cheap price but has long time delivery will disturb the production process. Therefore, it is very important to consider another factors apart from prices such as quality and delivery time. In maintaining the short core stock, a supplier's priority is needed to send raw materials continuously or even make work contracts. Table 1 shows the demand for plywood products for 1 month or 4 periods. The data on plywood product demand are obtained from the results of forecasting of past demand, then converted into a demand of short core raw material. One piece of plywood unit requires 4 pieces of shortcore. Table 2 shows the purchase price and delivery time of each supplier.

Table 1. Demand

\begin{tabular}{|c|c|c|}
\hline Periode & Plywood (pcs) & Shortcore (pcs) \\
\hline 1 & 9,306 & 37224 \\
\hline 2 & 8,176 & 32668 \\
\hline 3 & 14,758 & 59032 \\
\hline 4 & 9,941 & 39764 \\
\hline
\end{tabular}

Table 2. The Purchasing price and supplier's delivery time

\begin{tabular}{|c|c|c|c|}
\hline Suppliers & $\begin{array}{c}\text { Capacity } \\
\text { (pcs) }\end{array}$ & $\begin{array}{c}\text { Price } \\
\mathbf{( R p )}\end{array}$ & $\begin{array}{c}\text { Delivery time } \\
\text { (days) }\end{array}$ \\
\hline 1 & 22050 & 6,800 & 2 \\
\hline 2 & 18624 & 6,700 & 3 \\
\hline 3 & 10500 & 5,900 & 2 \\
\hline 4 & 6900 & 6,650 & 4 \\
\hline 5 & 9000 & 5,950 & 1 \\
\hline 6 & 2225 & 5,300 & 1 \\
\hline 7 & 8000 & 6,600 & 4 \\
\hline 8 & 1298 & 6,700 & 2 \\
\hline
\end{tabular}

In addition, The holding cost is calculated from the capital costs and electricity costs of the storage warehouse. The holding cost is Rp. $100 /$ pcs/period. The ordering cost is Rp 5,000 /order. The initial short core inventory in the previous period is 3,200 pcs. Running the ILP model by Lingo software results an optimum global solution with the value of the objective function, TC $=1,045,840,000$. Tables $3-6$ show the solutions of selected supplier and order quantity allocations for periods 1-4.

Table 3. The Selected Suppliers and Order Quantitty Allocation in Period 1

\begin{tabular}{|c|c|}
\hline Suppliers & Quantity (pcs) \\
\hline 1 & 0 \\
\hline 2 & 0 \\
\hline 3 & 10,500 \\
\hline 4 & 6,160 \\
\hline 5 & 9,000 \\
\hline 6 & 2,225 \\
\hline 7 & 8,000 \\
\hline 8 & 0 \\
\hline Safety stock in period 1 & 1,861 \\
\hline
\end{tabular}

Table 3 shows that the results of running period 1 indicate that the selected suppliers are suppliers 3, 4, 5, 6 and 7 . The quantity of orders allocated to selected suppliers are suppliers 3 $=10,500$ pcs, suppliers $4=6160$ pcs, suppliers $5=$ 9000 pcs, supplier $6=2225$ pcs, and supplier $7=$ 8000 pcs. The quantity of raw material ordered in the period 1 is 35,885 pcs, which are used to fulfill orders with initial inventory of 3,200 pcs. The rest of the raw material will be an inventory of period $1\left(I_{1}\right.$ $=1,861$ pcs .

Table 4. The Selected Suppliers and Order Quantitty Allocation in Period 2

\begin{tabular}{|c|c|}
\hline Suppliers & Quantity (pcs) \\
\hline 1 & 0 \\
\hline 2 & 0 \\
\hline 3 & 10,500 \\
\hline 4 & 6,519 \\
\hline 5 & 9,000 \\
\hline 6 & 2,225 \\
\hline
\end{tabular}




\begin{tabular}{|c|c|}
\hline 7 & 8,000 \\
\hline 8 & 0 \\
\hline Safety stock in period 2 & 5,437 \\
\hline
\end{tabular}

The results of running period 2 in table 4 show that the selected suppliers are suppliers 3,4 , 5,6 and 7. The order quantity allocation to each supplier are supplier $3=10,500$ pcs, supplier $4=$ 6,519 pcs, supplier $5=9,000$ pcs, supplier $6=$ 2,225 pcs and suppliers $7=8,000$ pcs. The total order for raw materials in the period 2 is 36,244 pcs. Total orders to suppliers in the period 2 is 32,440 , and the inventory in the period $2, I_{2}=5,437$ pcs.

Table 5. The Selected Suppliers and Order Quantitty Allocation in Period 3

\begin{tabular}{|c|c|}
\hline Suppliers & Quantity (pcs) \\
\hline 1 & 0 \\
\hline 2 & 18,624 \\
\hline 3 & 10,500 \\
\hline 4 & 6,900 \\
\hline 5 & 9,000 \\
\hline 6 & 2,225 \\
\hline 7 & 8,000 \\
\hline 8 & 1,298 \\
\hline Safety stock in period 3 & 2,952 \\
\hline
\end{tabular}

The results of running period 3 in table 5 show that the selected suppliers to supply the raw materials are about 7 suppliers. This is due to the large demand for short core material. Order quantity allocation to each supplier are supplier $2=18,624$ pcs, supplier $3=10,500$ pcs, supplier $4=6,900$ pcs, supplier $5=9,000$ pcs, supplier $6=2,225$ pcs, supplier $7=8,000$ pcs, supplier 8 is 2,225 pcs, supplier 8 is 8,000 pcs, supplier 8 is 1,298 pcs. The total order of shortcore to all suppliers is 56,547 pcs. The initial inventory of period 3 is 5,437 pcs and the final inventory in the period 3 is 2,952 pcs.

Table 6. The Selected Suppliers and Order Quantitty Allocation in Period 4

\begin{tabular}{|c|c|}
\hline Suppliers & Quantity (pcs) \\
\hline 1 & 0 \\
\hline 2 & 2,175 \\
\hline
\end{tabular}

\begin{tabular}{|c|c|}
\hline 3 & 10,500 \\
\hline 4 & 6,900 \\
\hline 5 & 9,000 \\
\hline 6 & 2,225 \\
\hline 7 & 8,000 \\
\hline 8 & 0 \\
\hline Safety stock in period 4 & 1,988 \\
\hline
\end{tabular}

Table 6 is the result of running lingo in period 4. The selected suppliers in period 4 are supplier 2 , $3,4,5,6$, and 7 . The order quantity allocation to each supplier are supplier $2=2,175$ pcs, supplier 3 $=10,500$ pcs, supplier $4=6,900$ pcs, supplier $5=$ 9,000 pcs, supplier $6=2,225$ pcs and supplier $7=$ 8,000 pcs. The total quantity of raw materials ordered in the period 4 is 38,800 pcs with an initial inventory of 2,952 pcs and the final inventory in the period 4 is 1,988 pcs.

\section{Sensitivity Analisis}

Sensitivity analysis is used to find out whether changes in parameter values cause solution changes. Sensitivity analysis is carried out on two parameters, both are supplier and demand capacity.

1. Sensitivity Analisis of supplier capacity Changes in the value of the supplier capacity parameter are carried out by increasing the capacity of each supplier by $25 \%$ and $40 \%$ and reducing the capacity of each supplier by $25 \%$ and $40 \%$.

Table 7. Sensitivity Analisis of supplier capacity in Period 1

\begin{tabular}{|c|c|c|c|c|c|}
\hline \multirow{2}{*}{ Suppliers } & \multicolumn{5}{|c|}{ Quantity (pcs) } \\
\cline { 2 - 6 } & baseline & $\mathbf{- 2 5 \%}$ & $\mathbf{- 4 0 \%}$ & $\mathbf{+ 2 5 \%}$ & $\mathbf{+ 4 0 \%}$ \\
\hline 1 & 0 & 0 & 9,354 & 0 & 0 \\
\hline 2 & 0 & 8,416 & 11,175 & 0 & 0 \\
\hline 3 & 10,500 & 7,875 & 6,300 & 13,125 & 14,700 \\
\hline 4 & 6,160 & 5,175 & 4,140 & 0 & 0 \\
\hline 5 & 9,000 & 6,750 & 5,400 & 11,250 & 12,600 \\
\hline 6 & 2,225 & 1,669 & 1,335 & 2,782 & 3,115 \\
\hline 7 & 8,000 & 6,000 & 4,800 & 8,729 & 5,470 \\
\hline 8 & 0 & 0 & 779 & 0 & 0 \\
\hline
\end{tabular}


We can see from table 7 that the initial solutions of selected suppliers are suppliers $2,3,5,6$, and 7 to supply the short core material. When supplier capacity is reduced by $25 \%$, selected suppliers changed and added suppliers 1 . When supplier capacity is reduced by $40 \%$, eight suppliers are instead selected to supply raw materials. The composition of selected suppliers also changed when supplier capacity is increased by $25 \%$ and $40 \%$. The new selected suppliers are suppliers 3, 5, 6 and 7. The increase and decrease in supplier capacity cause the change of selected suppliers. So that it can be said that the parameter of supplier capacity is a sensitive parameter.

Table 8. Sensitivity Analisis of supplier capacity in

Period 2

\begin{tabular}{|c|c|c|c|c|c|}
\hline \multirow{2}{*}{ Suppliers } & \multicolumn{5}{|c|}{ Quantity (pcs) } \\
\cline { 2 - 6 } & baseline & $\mathbf{- 2 5 \%}$ & $\mathbf{- 4 0 \%}$ & $\mathbf{+ 2 5 \%}$ & $\mathbf{+ 4 0 \%}$ \\
\hline 1 & 0 & 0 & 13,230 & 0 & 0 \\
\hline 2 & 0 & 6,375 & 11,175 & 0 & 0 \\
\hline 3 & 10,500 & 7,875 & 6,300 & 13,125 & 14,700 \\
\hline 4 & 6,519 & 5,175 & 4,140 & 0 & 0 \\
\hline 5 & 9,000 & 6,750 & 5,400 & 11,250 & 12,600 \\
\hline 6 & 2,225 & 1,669 & 1,335 & 2,782 & 3,115 \\
\hline 7 & 8,000 & 6,000 & 4,800 & 5,284 & 2,025 \\
\hline 8 & 0 & 0 & 779 & 0 & 0 \\
\hline
\end{tabular}

Table 9. Sensitivity Analisis of supplier capacity in Period 3

\begin{tabular}{|c|c|c|c|c|c|}
\hline \multirow{2}{*}{ Suppliers } & \multicolumn{5}{|c|}{ Quantity (pcs) } \\
\cline { 2 - 6 } & baseline & $\mathbf{- 2 5 \%}$ & $\mathbf{- 4 0 \%}$ & $\mathbf{+ 2 5 \%}$ & $\mathbf{+ 4 0 \%}$ \\
\hline 1 & 0 & 16,538 & 13,230 & 0 & 0 \\
\hline 2 & 18,624 & 13,968 & 11,175 & 14,570 & 9,076 \\
\hline 3 & 10,500 & 7,875 & 6,300 & 13,125 & 14,700 \\
\hline 4 & 6,900 & 5,175 & 4,140 & 8,625 & 9,660 \\
\hline 5 & 9,000 & 6,750 & 5,400 & 11,250 & 12,600 \\
\hline 6 & 2,225 & 1,669 & 1,335 & 2,782 & 3,115 \\
\hline 7 & 8,000 & 6,000 & 4,800 & 10,000 & 11,200 \\
\hline 8 & 1,298 & 974 & 779 & 0 & 0 \\
\hline
\end{tabular}

We can see from table 8 that the decrease in supplier capacity in the period 2 by $25 \%$ causes supplier 2 to be the selected supplier. The decrease in supplier capacity by $40 \%$ causes the eight selected suppliers to supply short core material. Selected suppliers include suppliers 3.5,6, and 7 when supplier capacity is increased by $25 \%$ and $40 \%$.

Table 9 shows that 7 suppliers were selected in the initial conditions, they are suppliers 2, 3,4, 5,6, and 7. The composition of the selected suppliers changed to be all selected when the supplier capacity is reduced by $25 \%$ and $40 \%$. When the supplier capacity is increased by $25 \%$ and $40 \%$, the selected supplier is suppliers 2,3,4,5,6 and 7 .

Table 10. Sensitivity Analisis of supplier capacity in Period 4

\begin{tabular}{|c|c|c|c|c|c|}
\hline \multirow{2}{*}{ Suppliers } & \multicolumn{5}{|c|}{ Quantity (pcs) } \\
\cline { 2 - 6 } & baseline & $\mathbf{- 2 5 \%}$ & $\mathbf{- 4 0 \%}$ & $\mathbf{+ 2 5 \%}$ & $\mathbf{+ 4 0 \%}$ \\
\hline 1 & 0 & 0 & 0 & 0 & 0 \\
\hline 2 & 2,175 & 11,332 & 11,175 & 0 & 0 \\
\hline 3 & 10,500 & 7,875 & 6,300 & 13,125 & 14,700 \\
\hline 4 & 6,900 & 5,175 & 4,140 & 1,644 & 0 \\
\hline 5 & 9,000 & 6,750 & 5,400 & 11,250 & 12,600 \\
\hline 6 & 2,225 & 1,669 & 1,335 & 2,782 & 3,115 \\
\hline 7 & 8,000 & 6,000 & 4,800 & 10,000 & 8,385 \\
\hline 8 & 0 & 0 & 678 & 0 & 0 \\
\hline
\end{tabular}

We can see from table 10 that the initial solution of selected suppliers in period 4 are 6 suppliers consisting of suppliers 2,3,4,5,6, and 7. This composition does not change even though the supplier capacity is reduced by $25 \%$. The decrease in supplier capacity by $40 \%$ cause the changes of selected suppliers. The increase in supplier capacity by $25 \%$ cause the composition of suppliers changed to 5 suppliers which included suppliers 3,4,5,6, and 7. The increase in capacity of supplier cause the selected suppliers to change. The changes in supplier capacity in table 7-10 above cause changes in solution, so the parameter of supplier capacity is the sensitive parameter. 


\section{Sensitivity Analisis of demand}

Changes in the parameter value of the demand is made by increasing the demand of short core material by $25 \%$ and $40 \%$ and reducing it by $25 \%$ and $40 \%$.

Table 11. The sensitivity analisis of demand in

Period 1

\begin{tabular}{|c|c|c|c|c|c|}
\hline \multirow{2}{*}{ Suppliers } & \multicolumn{5}{|c|}{ Quantity (pcs) } \\
\cline { 2 - 6 } & baseline & $\mathbf{- 2 5 \%}$ & $\mathbf{- 4 0 \%}$ & $\mathbf{+ 2 5 \%}$ & $\mathbf{+ 4 0 \%}$ \\
\hline 1 & 0 & 0 & 0 & 0 & 0 \\
\hline 2 & 0 & 0 & 0 & 0 & 0 \\
\hline 3 & 10,500 & 10,500 & 10,500 & 10,500 & 10,500 \\
\hline 4 & 6,160 & 0 & 0 & 0 & 0 \\
\hline 5 & 9,000 & 9,000 & 2,425 & 6,613 & 9,000 \\
\hline 6 & 2,225 & 2,225 & 2,225 & 2,225 & 2,225 \\
\hline 7 & 8,000 & 4,593 & 0 & 0 & 5,989 \\
\hline 8 & 0 & 0 & 0 & 0 & 0 \\
\hline
\end{tabular}

Table 11 shows that the decrease in demand by $25 \%$ and $40 \%$ causes the changes of the selected supplier. At a $40 \%$ decrease in demand and a $25 \%$ increase, selected supplier solutions include suppliers 3.5 and 6 . Changes in demand parameters cause changes in selected supplier solutions. This can be notified that the request parameter is sensitive. Changes to the demand value cause changes to the selected supplier solution. The solution in the period 2 in table 12 has the same solution of the selected supplier as period 1.

Table 12. The sensitivity analisis of demand in

Period 2

\begin{tabular}{|c|c|c|c|c|c|}
\hline \multirow{2}{*}{ Suppliers } & \multicolumn{5}{|c|}{ Quantity (pcs) } \\
\cline { 2 - 6 } & baseline & $\mathbf{- 2 5 \%}$ & $\mathbf{- 4 0 \%}$ & $\mathbf{+ 2 5 \%}$ & $\mathbf{+ 4 0 \%}$ \\
\hline 1 & 0 & 0 & 0 & 0 & 0 \\
\hline 2 & 0 & 0 & 0 & 0 & 0 \\
\hline 3 & 10,500 & 10,500 & 10,500 & 10,500 & 10,500 \\
\hline 4 & 6,160 & 0 & 0 & 0 & 0 \\
\hline 5 & 9,000 & 9,000 & 3,955 & 8,526 & 9,000 \\
\hline 6 & 2,225 & 2,225 & 2,225 & 2,225 & 2,225 \\
\hline 7 & 8,000 & 2,402 & 0 & 0 & 3,687 \\
\hline 8 & 0 & 0 & 0 & 0 & 0 \\
\hline
\end{tabular}

Table 13. The sensitivity analisis of demand in

Period 3

\begin{tabular}{|c|c|c|c|c|c|}
\hline \multirow{2}{*}{ Suppliers } & \multicolumn{5}{|c|}{ Quantity (pcs) } \\
\cline { 2 - 6 } & baseline & $\mathbf{- 2 5 \%}$ & $\mathbf{- 4 0 \%}$ & $\mathbf{+ 2 5 \%}$ & $\mathbf{+ 4 0 \%}$ \\
\hline 1 & 0 & 0 & 0 & 0 & 0 \\
\hline 2 & 0 & 8,637 & 0 & 0 & 10,903 \\
\hline 3 & 10,500 & 10,500 & 10,500 & 10,500 & 10,500 \\
\hline 4 & 6,160 & 6,900 & 0 & 1,244 & 6,900 \\
\hline 5 & 9,000 & 9,000 & 9,000 & 9,000 & 9,000 \\
\hline 6 & 2,225 & 2,225 & 2,225 & 2,225 & 2,225 \\
\hline 7 & 8,000 & 8,000 & 3,050 & 8,000 & 8,000 \\
\hline 8 & 0 & 0 & 0 & 0 & 0 \\
\hline
\end{tabular}

We can see from table 13 that the increase in the quantity of short core demand in the period 3 by $25 \%$ does not change the initial solution. Whereas decrease in the quantity of demand by $25 \%$ and an increase in the quantity of demand by $40 \%$ led to a change in the initial solution.

Table 14. The sensitivity analisis of demand in Period 4

\begin{tabular}{|c|c|c|c|c|c|}
\hline \multirow{2}{*}{ Suppliers } & \multicolumn{5}{|c|}{ Quantity (pcs) } \\
\cline { 2 - 6 } & baseline & $\mathbf{- 2 5 \%}$ & $\mathbf{- 4 0 \%}$ & $\mathbf{+ 2 5 \%}$ & $\mathbf{+ 4 0 \%}$ \\
\hline 1 & 0 & 0 & 0 & 0 & 0 \\
\hline 2 & 0 & 0 & 0 & 0 & 0 \\
\hline 3 & 10,500 & 10,500 & 10,500 & 10,500 & 10,500 \\
\hline 4 & 6,160 & 6,900 & 0 & 0 & 833 \\
\hline 5 & 9,000 & 0 & 4,275 & 8,525 & 9,000 \\
\hline 6 & 2,225 & 2,225 & 2,225 & 2,225 & 2,225 \\
\hline 7 & 8,000 & 7,376 & 0 & 0 & 8,000 \\
\hline 8 & 0 & 0 & 0 & 0 & 0 \\
\hline
\end{tabular}

We can see from table 13 that the increase in the quantity of short core demand in the period 3 by $25 \%$ does not change the initial solution. Whereas decrease in the quantity of demand by $25 \%$ and an increase in the quantity of demand by $40 \%$ led to a change in the initial solution. Table 14 shows that the increase in the quantity of demand in the period 4 by $40 \%$ does not cause a change in the initial solution. A decrease in demand by $25 \%$ causes supplier 5 to exit the initial solution. The decrease in the quantity of demand by $40 \%$ and the increase in the quantity of demand by $25 \%$ led to 
the selected supplier solution of 3, They are suppliers 3,5 and 6 .

\section{CONCLUSION.}

Supplier selection and order allocation are one of the important process to maintain the continuity of production. Determination of the selected suppliers and order allocation is done by developing an integer linear programming model. The developed model is able to select suppliers per period. The model is also able to determine the allocation of raw material to selected suppliers. Sensitivity analysis is done to find out which parameters are sensitive. The results of the sensitivity analysis indicate that the parameters of supplier capacity and demand are sensitive parameters.

\section{BIBLIOGRAPHY.}

Amid, A., Ghodsypur, S.H., \& O'Brien, C.A., 2011. Weighted Max-Min Model For Fuzzy Multi Objective Supplier Selection in a Supply Chain. International Journal Production Economics, vol. 131, pp.139145.

Anthony, T.F. \& Buffa, F.P., 1977. Strategic Purchasing scheduling. Journal Purchasing Material Management, 13(3), pp.27-31.

Chaudhry, S.S., Forst, F.G., \& Zydiak, J.I., 1993. Vendor Selection Wih Price Break. European Journal Operation Research, 70(1), pp.52-56.

Ghodyspour, S.H. \& O'Brien, C.O., 2001. The Total Cost Of Logistics In Supplier Selection Under
Conditions Of Muliple Sourcing, Multiple Criteria And Capacity Constraint. International Journal Production Economics, 73(1), pp.15-27.

Jayaraman, V., Srivastava, R., \& Benton, W.C., 1999. Supplier Selection And Order Quantity Allocation a Comprehensive Model. Journal Supply Chain Management, 35(2), pp.50-58.

Mendosa, A. \& Ventura, J.A., 2012. Analytical Models For Supplier Selection And Order Quantity Allocation. Applied Mathematicak Modelling, vol. 36, pp.3826-3835.

Moore, D.I. \& Fearon, H.E., 1973. Computer Assisted Decision Making In Purchasing. Journal Purchasing, 9(4), pp.5-25.

Narasimhan, R. \& Staynoff, K., 1986. Opimizing Agregate Procurement Allocation Decisions. Journal Purchasing Material Management, 22(1), pp.23-30.

Tsai, Y. L., Yang, Y.J., \& Lin C.H., 2010. A Dynamic Decision Approach For Supplier Selection Using Ant-Colony System. Expert System with Applications, vol.37, pp.8313-8321.

Yang, C.C., \& Chen, B.S., 2006. Supplier Selection Using Combined Analytical Hierarchy Process And Grey Relational Analysis. Journal of Manufacturing Technology Management, 17(7), pp.926-941. 